Original Article (short paper)

\title{
Construct Validity of the Spanish Version of the CHAMPS Questionnaire for institutionalized patients over 65 years old
}

\author{
José M. Cancela \\ Carlos Ayán \\ Miguel A. Sánchez-Lastra \\ Ángel Casal \\ HealthyFit Research Group, University of Vigo, Pontevedra, Spain.
}

\begin{abstract}
This study investigates the construct validity of the Spanish version of the CHAMPS questionnaire with institutionalized older adults between the ages of 74 and 90 . Seven days of accelerometer data were collected from 52 participants (mean age $82.40 \pm 8.26$ years), followed by the administration of CHAMPS. The Barthel Index and the Chair Stand Test were used to assess functional independence and fitness levels. The four scores yielded by CHAMPS showed a low-to-moderate agreement with the data derived from the accelerometer $(\mathrm{r}=0.253-0.385)$ and with the Barthel Index ( $\mathrm{r}=0.313-0.519)$, but no association was established with fitness levels. Additionally, no significant correlations were observed between CHAMPS and the accelerometer when cognitive impairment was considered. The results imply that the Spanish version of CHAMPS shows construct validity to estimate the amount of physical activity performed by institutionalized older adults without cognitive impairment.
\end{abstract}

Keywords: validity, physical activity,questionnaire,older adults, institutional care.

\section{Introduction}

Various studies have highlighted the benefits of physical activity (PA) performance in older adults on physical, cognitive, and functional levels ${ }^{1}$. For this reason, one of the main health strategies aimed at this group is the promotion of $\mathrm{PA}^{2}$. For this purpose, it is fundamental to ascertain efficient resources in order to pinpoint the level of PA that has been reached after a period of time. This would allow experts to determine the baseline from which an adequate prescription of PA performance could be established, as well as to identify the effects of the interventions with this objective in mind. In this regard, PA recall performance questionnaires are considered the most effective tool given their low-cost, ease of administration, and capacity for simultaneous assessment in larger samples ${ }^{3}$.

In spite of this, research is still scarce regarding the psychometric properties of the Spanish versions of questionnaires that are specifically tailored for the assessment of PA performance in older adults ${ }^{4-7}$. It has been suggested that the questionnaire that was created on the basis of the study entitled "Community Healthy Activities Model Program for Seniors," also known as CHAMPS $^{8}$, is the most advisable resource in situations where the main goal is to estimate the prevalence of PA performance in older adults, primarily because the questionnaire features a series of psychometric properties that are suitable for this purpose ${ }^{9}$. However, from an epidemiological approach, the use of CHAMPS with Spanish older populations would present a number of methodological limitations since the psychometric properties of the adapted version of CHAMPS for Hispanic populations have not yet been investigated ${ }^{10}$. Moreover, this version was later modified to assess its applicability in Puerto Rican populations, but only its internal consistency was analyzed by testing a very small sample of older adults between the ages of 65 and $90^{11}$. Consequently, the degree of validity of that version remains to be determined when administered to adult Spanish populations. In addition, it has been noted that CHAMPS validity behaves differently in institutionalized older adults, a group for which a very low level of affinity has been detected between the amount of PA estimated by the questionnaire and the amount registered through accelerometry ${ }^{12}$. Hence, this particular line of research is yet to be fully exploited.

Under these circumstances, the present study investigates the validity of a Spanish adaptation of the CHAMPS questionnaire for institutionalized older adults between the ages of 74 and 90 .

\section{Methods}

Participants in this study were recruited through a collaboration agreement signed between the University of "Vigo" and "Fundación San Rosendo", a company that specializes in geriatric center management. The inclusion criteria were the following: (a)being over 65 years' old; (b) residing in a geriatric center; and (c)presenting mobility autonomy, in other words, being able to move freely without the help of another person. Individuals who presented any type of pathology that could prevent them from carrying out the tests included in the study, or otherwise expressed their desire not to take part either personally or through a family member or caretaker, were also excluded. All participants and their families were informed of the aims and characteristics of the research and their informed consent was obtained. Research approval was granted by the Ethics Committee of the University of " $\mathrm{X}$ ". 


\section{Assessment}

Sociodemographic and cultural characteristics. Age, gender, and educational level of participants were obtained from the medical histories provided by the appropriate geriatric centers.

Cognitive functionality. The presence of cognitive deterioration was determined through an analysis of the results obtained from a Spanish language adaptation of the Mini-Cog Test $(\mathrm{MCT})^{13}$ and Pfeiffer's questionnaire ${ }^{14}$, which were recorded in each patient's medical history.

CHAMPS questionnaire. The present study employed the Puerto Rican version of CHAMPS ${ }^{11}$ that originally included 41 items. With the purpose of adapting questionnaire entries to the characteristics of institutionalized persons, a number of items were discarded, such as related activities that were not attested in the environment of the geriatric centers where the study was conducted. These activities included playing golf or tennis, skating, going to meeting places, carrying heavy bags, etc. The resulting version included 31 items involving the frequency (times per week) and duration of physical activities (classified using six categories: less than $1 \mathrm{~h} \cdot \mathrm{wk}^{-1} ; 1-2.5 \mathrm{~h} \cdot \mathrm{wk}^{-1} ; 3-4.5 \mathrm{~h} \cdot \mathrm{wk}^{-1}$; $5-6.5 \mathrm{~h} \cdot \mathrm{wk}^{-1} ; 7-8.5 \mathrm{~h} \cdot \mathrm{wk}^{-1}$; and 9 or more $\mathrm{h} \cdot \mathrm{wk}^{-1}$ ).

Activities that were featured in the final modified version included walking leisurely (fast or briskly), cycling, light gardening, light housekeeping, jogging, swimming, light exercises to maintain physical condition (stretching, Tai-Chi), taking part in physical therapy or exercise fitness programs, doing aerobics, engaging in muscular strength training (free-weights, calisthenics, machines), dancing, playing a musical instrument, reading, and playing cards.

The CHAMPS questionnaire yields four separate scores: (1) total caloric energy expenditure per week based upon "all" activities that would likely impact health; (2) caloric energy expenditure per week based upon moderate-to-vigorous intensity activity; (3) frequency per week (in minutes) of engagement in total meaningful activities; and (4) frequency per week (in minutes) of engagement in moderate-to-vigorous intensity physical activities.

To estimate energy expenditure, metabolic equivalents (METS) were used according to the compendium of activities that were originally designed in conjunction with the questionnaire, and later modified and completed by Hekler et al. ${ }^{15}$. In this regard, a value of 3 METS or higher was given to moderate-tovigorous intensity physical activities.

The criterion validity of the CHAMPS questionnaire to estimate the amount of PA performed was contrasted with the help of the accelerometer ActiGraph GT3X (ActiGraph, LLC, Pensacola, FL, USA), an instrument that has been considered appropriate for these purposes ${ }^{16}$. In the present study, accelerations were registered with a sample frequency of $100 \mathrm{~Hz}$ and then filtered, digitalized, and compiled in periods of 60 seconds. The amount of PA performed was estimated in counts (minutes per day). ActiLife 5 (ActiGraph software, LLC, Pensacola, FL, USA) was employed to analyze the resulting data. Given that the amount of PA performed is related to the individual level of independence to complete everyday activities ${ }^{17}$ and to individual fitness levels ${ }^{18}$, participants in this study completed an adapted version of the Barthel Index (BI) ${ }^{19}$, and carried out the Chair StandTest with five repetitions ${ }^{20}$. The results from these tests were used as an indirect indicator to contrast CHAMPS validity.

\section{Procedure}

Initially, a doctor specialized in gerontology, a caregiver, and a specialist in physical exercise and old age with previous experience with institutionalized populations reviewed and analyzed the Puerto Rican version of the CHAMPS questionnaire. A consensus was reached on a final version comprising 31 items that would be used for the present study. Following this, general information about the questionnaire was presented and specific instructions on how the accelerometer worked was provided to the health personnel at each geriatric center, as well as to all participants and their families. With the purpose of determining the construct validity of the questionnaire, participants were asked to carry the accelerometer with them for one week. The device remained attached to their right thigh above the iliac crest while in standing position ${ }^{21}$, or around their dominant wrist while in sitting position ${ }^{22}$. It was expressed that they were to use the device from early in the morning until they went to bed at night, putting it aside only if they wished to have a bath or a shower, or needed to perform any kind of water-based activity. In addition, both the caretakers' and health personnel's collaboration was requested to guarantee that the indications stipulated at the beginning of the experiment were observed. The day after their weekly activity monitoring, health personnel at each geriatric center administered the CHAMPS questionnaire to the participants individually in an interview format.

\section{Statistical analysis}

A descriptive statistical analysis was conducted to summarize the main variables that were examined. For continuous variables, central tendency measures were used (mean, standard deviation, median, minimum, and maximum), while categorical variables were studied using percentages. This descriptive analysis was performed globally by stratifying the sample depending upon the presence or absence of cognitive deterioration. To contrast the normality of the data set, and take the size of the sample into account, the Shapiro-Wilk test was employed. The results indicated that all dependent variables presented a normal distribution, both when the sample was considered in groups and in stratified form, depending upon the level of cognitive deterioration ( $p>0.05$ ). Student's t-test for independent data was applied to identify statistically significant differences in the continuous variables depending upon the presence or absence of cognitive deterioration. A Pearson correlational analysis was performed to identify the degree of association between the CHAMPS questionnaire, the GT3X accelerometers, the Barthel Index, and the Chair Stand Test. The data set was studied using the SPSS Statistics software (Armonk, NY: IBM Corp.) version 22.0 for Windows with a significance level of $p<0.05$. 


\section{Results}

A total of 52 institutionalized older adults (average age $82.40 \pm 8.26$ years; $70 \%$ women) completed the tests. Individual characteristics as well as the mean values obtained in general and relative to the presence or absence of cognitive deterioration, are shown in Table 1. According to the results observed in the adapted version of MCT and Pfeiffer's questionnaire, it was evident that $69.2 \%$ of the sample presented with cognitive deterioration.

Table 1 Characteristics and mean values obtained from the sample relative to the presence or absence of cognitive deterioration.

\begin{tabular}{|c|c|c|c|c|c|c|c|c|c|c|c|c|}
\hline & \multicolumn{4}{|c|}{$\begin{array}{l}\text { Total sample } \\
\quad \mathrm{n}=\mathbf{5 2}\end{array}$} & \multicolumn{4}{|c|}{$\begin{array}{l}\text { Absence of cognitive deterioration } \\
\qquad n=16\end{array}$} & \multicolumn{4}{|c|}{$\begin{array}{l}\text { Presence of cognitive deterioration } \\
\qquad n=36\end{array}$} \\
\hline & $\begin{array}{c}\text { Mean } \\
(S D)\end{array}$ & Median & Min & $\operatorname{Max}$ & $\begin{array}{c}\text { Mean } \\
(S D)\end{array}$ & Median & Min & $\operatorname{Max}$ & $\begin{array}{l}\text { Mean } \\
(S D)\end{array}$ & Median & Min & $\operatorname{Max}$ \\
\hline Gender ( $\%$ female $)$ & $72.20 \%$ & - & - & - & $75.00 \%$ & - & - & - & $69.40 \%$ & - & - & - \\
\hline Age in years & $\begin{array}{l}82.40 \\
(8.26)\end{array}$ & 85.00 & 65.00 & 95.00 & $\begin{array}{l}78.67 \\
(9.17)\end{array}$ & 79.00 & 65.00 & 91.00 & $\begin{array}{l}86.13 \\
(7.68)\end{array}$ & 85.00 & 65.00 & 95.00 \\
\hline $\begin{array}{l}\text { Educational level (\% } \\
\text { primary) }\end{array}$ & $95.38 \%$ & - & - & - & $96.32 \%$ & - & - & - & $94.44 \%$ & - & - & - \\
\hline MCT score & $\begin{array}{l}18.30 \\
(8.50)\end{array}$ & 21.00 & 0.00 & 31.00 & $\begin{array}{l}25.58 \\
(6.33)\end{array}$ & 27.50 & 25.00 & 31.00 & $\begin{array}{l}11.02 * * \\
(8.65)\end{array}$ & 16.00 & 0.00 & 24.00 \\
\hline Pfeiffer Test & $\begin{array}{c}4.25 \\
(13.55)\end{array}$ & 3.00 & 0.00 & 90.00 & $\begin{array}{c}1.17 \\
(2.29)\end{array}$ & 0.00 & 0.00 & 8.00 & $\begin{array}{c}7.32 * \\
(15.63)\end{array}$ & 5.00 & 0.00 & 90.00 \\
\hline Barthel Index & $\begin{array}{c}51.28 \\
(29.40)\end{array}$ & 45.00 & 5.00 & 100.00 & $\begin{array}{l}63.33 \\
(29.64)\end{array}$ & 77.50 & 15.00 & 100.00 & $\begin{array}{l}39.23 * * \\
(21.63)\end{array}$ & 35.00 & 5.00 & 95.00 \\
\hline Five chair stands (s) & $\begin{array}{l}18.03 \\
(6.23)\end{array}$ & 16.25 & 9.80 & 34.80 & $\begin{array}{l}15.44 \\
(4.78)\end{array}$ & 14.64 & 9.80 & 25.30 & $\begin{array}{l}20.62 \\
(6.44)\end{array}$ & 20.20 & 10.30 & 34.80 \\
\hline \multicolumn{13}{|l|}{ CHAMPS Questionnaire } \\
\hline $\begin{array}{l}\text { Moderate and greater } \\
\text { intensity measures. } \\
\text { Caloric expenditure } \\
\text { per week in at least } \\
\text { moderate intensity } \\
\text { physical activities } \\
(\text { MET } \geq 3.0)\end{array}$ & $\begin{array}{l}1,375.72 \\
(789.23)\end{array}$ & $1,312.96$ & 0.00 & $3,180.28$ & $\begin{array}{l}1,633.90 \\
(933.83)\end{array}$ & $1,663.08$ & 612.71 & $3,180.28$ & $\begin{array}{l}1,118.45 \\
(686.53)\end{array}$ & $1,312.96$ & 0.00 & $2,149.36$ \\
\hline $\begin{array}{l}\text { Minutes per week } \\
\text { in at least moderate } \\
\text { intensity physical } \\
\text { activities }(M E T \geq 3.0)\end{array}$ & $\begin{array}{c}425.00 \\
(244.12)\end{array}$ & 315.00 & 0.00 & $1,050.00$ & $\begin{array}{l}498.75 \\
(287.12)\end{array}$ & 525.00 & 210.00 & $1,050.00$ & $\begin{array}{c}353.50 \\
(216.21)\end{array}$ & 315.00 & 0.00 & 840.00 \\
\hline $\begin{array}{l}\text { All activities measure. } \\
\text { Caloric expenditure } \\
\text { per week in all listed } \\
\text { physical activities }\end{array}$ & $\begin{array}{l}3,624.26 \\
(2141.95)\end{array}$ & $2,625.92$ & $1,475.06$ & 9326.87 & $\begin{array}{c}4,508.91 \\
(2,981.78)\end{array}$ & $2,966.32$ & 1993.75 & $9,326.87$ & $\begin{array}{l}2,741.88^{*} \\
(1,599.83)\end{array}$ & $2,562.70$ & $1,475.06$ & $6,107.69$ \\
\hline $\begin{array}{l}\text { Minutes per week } \\
\text { in all listed physical } \\
\text { activities }\end{array}$ & $\begin{array}{l}1,849.50 \\
(975.33)\end{array}$ & $1,470.00$ & 210.00 & 4095.00 & $\begin{array}{c}2,321.67 \\
(1,241.76)\end{array}$ & $1,575.00$ & 840.00 & $4,095.00$ & $\begin{array}{c}1,378.33 * \\
(749.87)\end{array}$ & $1,312.50$ & 210.00 & $1,940.00$ \\
\hline
\end{tabular}

Note. ${ }^{* *} \mathrm{p}<0.001 ;{ }^{*} \mathrm{p}<0.05$

The total estimated amount of PA performed provided by the CHAMPS questionnaire was 3,624.26 $\pm 2,141.95 \mathrm{kcal} /$ week for the sample as a whole, with statistically significant differences found depending upon the absence or presence of cognitive deterioration (4,500 vs. 2,740 kcal/week, respectively).

For the entire sample, a significant statistical correlation was observed between the four scores of the CHAMPS questionnaire and the amount of PA performed according to the data derived from the accelerometer $(\mathrm{r}=0.253-0.385)$. These four scores also showed statistically significant associations with the degree of independence determined using the BI ( $\mathrm{r}=0.313-0.519)$, but not with the results of the Chair Stand Test. Similar findings were attested in institutionalized participants without cognitive deterioration even though the degree of association between the CHAMPS questionnaire and the accelerometry, and the degree of association between 
the CHAMPS questionnaire and the BI, led to higher values in general $(\mathrm{r}=0.203-0.630$ and $\mathrm{r}=0.334-0.494$, respectively). The sub-sample of institutionalized individuals with cognitive deterioration also showed statistically significant associations, but only between the CHAMPS questionnaire and the BI $(r=0.279-0.368)$.

Table 2 Correlations established between the variables under study.

\begin{tabular}{|c|c|c|c|c|c|c|c|c|c|c|}
\hline & & \multicolumn{3}{|c|}{$\begin{array}{l}\text { Total sample } \\
\qquad \mathbf{n}=52\end{array}$} & \multicolumn{3}{|c|}{$\begin{array}{c}\text { Absence of cognitive } \\
\text { deterioration } \\
\mathbf{n}=16\end{array}$} & \multicolumn{3}{|c|}{$\begin{array}{c}\text { Presence of cognitive } \\
\text { deterioration } \\
n=36\end{array}$} \\
\hline & & $\begin{array}{c}\text { GT3X } \\
\text { accelerometer } \\
\text { Counts }\end{array}$ & $\begin{array}{l}\text { Barthel } \\
\text { Index }\end{array}$ & $\begin{array}{l}\text { Five } \\
\text { chair } \\
\text { stands }\end{array}$ & $\begin{array}{c}\text { GT3X } \\
\text { accelerometer } \\
\text { Count }\end{array}$ & $\begin{array}{l}\text { Barthel } \\
\text { Index }\end{array}$ & $\begin{array}{l}\text { Five } \\
\text { chair } \\
\text { stands }\end{array}$ & $\begin{array}{c}\text { GT3X } \\
\text { accelerometer } \\
\text { Counts }\end{array}$ & $\begin{array}{l}\text { Barthel } \\
\text { Index }\end{array}$ & $\begin{array}{l}\text { Five } \\
\text { chair } \\
\text { stands }\end{array}$ \\
\hline \multirow{2}{*}{$\begin{array}{l}\text { Moderate and } \\
\text { greater intensity } \\
\text { measures. Caloric } \\
\text { expenditure per } \\
\text { week in at least } \\
\text { moderate intensity } \\
\text { physical activities } \\
(\text { MET } \geq 3.0)\end{array}$} & $\begin{array}{l}\text { Pearson's } \\
\text { Correlation }\end{array}$ & $.253^{*}$ & $.383^{*}$ & -.274 & $.272 *$ & $.334 *$ & -.421 & .066 & $.329 *$ & -.175 \\
\hline & Sig. & .046 & .012 & .117 & .046 & .039 & .099 & .365 & .038 & .213 \\
\hline \multirow{2}{*}{$\begin{array}{l}\text { Minutes per week } \\
\text { in at least moderate } \\
\text { intensity physical } \\
\text { activities } \\
(\text { MET } \geq 3.0)\end{array}$} & $\begin{array}{l}\text { Pearson's } \\
\text { Correlation }\end{array}$ & $.258^{*}$ & $.313^{*}$ & -.236 & $.203^{*}$ & $.439 *$ & -.268 & .111 & $.279 *$ & -.296 \\
\hline & Sig. & .049 & .045 & .179 & .023 & .033 & .212 & .280 & .035 & .085 \\
\hline \multirow{2}{*}{$\begin{array}{l}\text { All activities } \\
\text { measures. Caloric } \\
\text { expenditure per } \\
\text { week in all listed } \\
\text { physical activities }\end{array}$} & $\begin{array}{l}\text { Pearson's } \\
\text { Correlation }\end{array}$ & $.287^{*}$ & $.498 * *$ & -.170 & $.477^{*}$ & $.392 *$ & -.343 & .122 & $.371 *$ & -.028 \\
\hline & Sig. & .045 & .002 & .369 & .037 & .049 & .183 & .276 & 0.31 & .452 \\
\hline \multirow{2}{*}{$\begin{array}{l}\text { Minutes per } \\
\text { week in all listed } \\
\text { physical activities }\end{array}$} & $\begin{array}{l}\text { Pearson's } \\
\text { Correlation }\end{array}$ & $.385^{*}$ & $.519 * *$ & -.132 & $.630^{*}$ & $.494^{*}$ & -.451 & .120 & $.368^{*}$ & -.185 \\
\hline & Sig. & .023 & .001 & .486 & .035 & .048 & .111 & .279 & .032 & .211 \\
\hline
\end{tabular}

Note. ${ }^{* *} \mathrm{p}<0.001 ; * \mathrm{p}<0.05$

\section{Discussion}

This study provides information about the construct validity of the CHAMPS questionnaire when administered to institutionalized Spanish older adults between the ages of 74 and 90 . The results could prove useful for professionals in the field of gerontology and physical exercise in search of an effective tool to estimate the amount of PA performed by this particular population.

The CHAMPS questionnaire includes two primary measures, minutes per week spent performing PA and calories per week expended in all physical activities, which make it possible to estimate the total amount of PA performed by the population surveyed. In this regard, the degree of validity shown by the CHAMPS questionnaire for the entire sample could be described as moderate, which is in agreement with previous findings. Particularly, Colbert, Matthews, Havighurst, Kim, and Schoeller ${ }^{23}$ indicated the existence of a degree of correlation of 0.52 between caloric expenditure, as estimated by this questionnaire, and counts per minute measured by the ActiGraph, while Hekler et al. ${ }^{15}$ reported that CHAMPS total activity scores were moderately associated with accelerometry minutes of corresponding intensity $(\rho=0.34)$. Likewise, Giles and Marshall ${ }^{24}$ reflected a similar level of agreement $(r=0.38)$ even though they employed a pedometer as a measure of objective assessment.

CHAMPS was developed to assess the potential outcomes of PA intervention and designed to be administered to populations of community-dwelling older adults. For this reason, the CHAMPS questionnaire seems to be the best choice to rank individuals with respect to their levels of physical energy expenditure $^{23}$. Nevertheless, little is known about the behavior of its psychometric properties among institutionalized persons and the same applies to its usefulness in populations with cognitive 
deterioration. The originality of the present study resides not only in assessing CHAMPS validity for Spanish populations, but also in putting forward data concerning its validity in institutionalized populations with and without cognitive deterioration. In this sense, CHAMPS attested a satisfactory degree of construct validity among institutionalized persons without cognitive deterioration, which opposes the observations of Harada, Chiu, King, Stewart ${ }^{12}$ who could not find any type of significant statistical association between the total estimated amount of PA performed according to the questionnaire and the data obtained from the accelerometry for this population.

These somewhat contradictory findings could have been due to methodological divergences between the studies. Indeed, the present research asked participants to wear the accelerometer during the week before answering the questionnaire, which could have facilitated their recall of the activities they had performed. Moreover, in Harada et al. (ibid.) participants completed the questionnaire themselves, while the present study preferred a face-to-face method of administration, which favors validity ${ }^{24}$. It should also be added that taking Harada, Chiu, King, Stewart's (ibid.) caloric expenditure as reference, this factor could be qualified as sedentary ${ }^{10}$, and it has been claimed that CHAMPS is not the most appropriate resource to assess sedentary behavior ${ }^{15,25}$, or even to estimate the amount of PA performed in populations where low-intensity activity is predominant ${ }^{26}$. However, the CHAMPS questionnaire proved to be an invalid tool to estimate the amount of PA performed in institutionalized populations with cognitive deterioration in this study.

In light of the fact that the energy expenditure levels reported by participants with cognitive deterioration was significantly lower than those of participants without cognitive deterioration, it could be concluded that leading a sedentary life might be the reason behind the lack of correlation between CHAMPS scores and accelerometer results. Nevertheless, despite levels of energy expenditure among participants with cognitive deterioration being lower than those reported in previous research studies carried out with cognitively healthy institutionalized persons using the same questionnaire ${ }^{27}$, according to Stewart, Mills, King, Haskell, Gillis, Ritter ${ }^{10}$ those participants could be qualified as somewhat active. In fact, the levels of energy expenditure that were reported in their case were considerably higher than those obtained from the CHAMPS questionnaire in non-institutionalized populations with possible cognitive deterioration ${ }^{28}$. For this reason, the lack of validity of the CHAMPS questionnaire in this particular subsample might be related to the fact that remembering the activities performed throughout the week could be challenging for this group. Indeed, the only PA recall questionnaire that has proven its validity to date in populations with cognitive deterioration is the One-day Recall ${ }^{29}$. In this regard, it is important to highlight that even though it has been suggested that administering CHAMPS to populations with cognitive deterioration might lead to missing data ${ }^{28}$, complications have not been reported from its administration to older adult populations with subjective and objective mild cognitive impairment ${ }^{30}$.

The present study confirmed a significant degree of association between the CHAMPS questionnaire and the participants' level of functional independence. Similarly, other studies have reported the existence of significant correlations between the estimated total amount of PA obtained from the questionnaire and the results gathered from performance-based physical function tests and self-reported physical functioning ${ }^{10,31}$. However, no correlation was found with the level of fitness when the Chair StandTest was employed, which contradicts previous observations in institutionalized populations ${ }^{32}$.

This lack of correlation could be due to the characteristics of the sample, and judging by the mean values obtained from both groups (with and without cognitive deterioration) in the Chair Stand Test, the level of muscular endurance of the sample population could be judged as very low ${ }^{33}$. In this regard, it has been stated that poor muscular fitness is an aspect that affects the validity of the PA recall questionnaire ${ }^{34}$. Further discussion on the subject has been limited as research experiments that have analyzed the degree of correlation between the CHAMPS questionnaire and the Chair Stand Test have not provided information about the mean values that resulted from the test ${ }^{10,12,32}$, and only one reported on the correlation coefficient obtained specifically from this test ${ }^{32}$.

In spite of the originality of the results presented here, it is necessary to acknowledge certain methodological weaknesses that may limit the generalization of results. Specifically, the ability to determine the validity of the CHAMPS questionnaire in institutionalized populations was affected by the reduced number of participants in the study sub-sample without cognitive deterioration and the lack of an aerobic fitness assessment test. In this respect, future studies should focus upon larger samples and include a more complete fitness level assessment to confirm these findings.

\section{Conclusion}

The CHAMPS questionnaire has shown adequate construct validity at the time of determining the amount of PA performed by institutionalized older adults. However, its use is discouraged for people with cognitive deterioration.

\section{Acknowledgments}

We thank Fundación San Rosendo and all the professionals in the centers that participated in the study

\section{References}

1. Bherer L, Erickson KI, Liu-Ambrose T. A review of the effects of physical activity and exercise on cognitive and brain functions in older adults. J Aging Res. 2013;2013:657508. doi: $10.1155 / 2013 / 657508$

2. Hupin D, Roche F, Gremeaux V, Chatard JC, Oriol M, Gaspoz JM, et al. Even a low-dose of moderate-to-vigorous physical activity 
reduces mortality by $22 \%$ in adults aged $\geq 60$ years: a systematic review and meta-analysis. Br J Sports Med. 2015;49(19):1262-7.

3. Helmerhorst HJ, Brage S, Warren J, Besson H, Ekelund U. A systematic review of reliability and objective criterion-related validity of physical activity questionnaires. Int J Behav Nutr Phys Act. 2012; 31(9):103. doi: 10.1186/1479-5868-9-103.

4. Cancela JM, Varela S, Álvarez MJ, Molina A, Ayán C, Martín V. Validity of a combined fibromyalgia (FM) questionnaires to assess physical activity levels in Spanish elderly women: An experimental approach. Arch Gerontol Geriatr. 2011;52(1): e56-e59.

5. De Abajo S, Larriba R, Marquez S. Validity and reliability of the Yale Physical Activity Survey in Spanish elderly. J Sports Med Phys Fitness. 2001;41(4):479-85.

6. Ruiz Comellas A, Pera G, Baena Díez JM, Mundet Tudurí X, Alzamora Sas T, Elosua R, et al. Validación de una versión reducida en español del cuestionario de actividad física en el tiempo libre de Minnesota (VREM). Rev Esp Salud Publica. 2012;86(5):495-508. doi: 10.4321/S1135-57272012000500004.

7. Vilaró J, Gimeno E, Férez NS, Hernando C, Díaz I, Ferrer M, et al. Actividades de la vida diaria en pacientes con enfermedad pulmonar obstructiva crónica: validación de la traducción española y análisis comparativo de 2 cuestionarios. Med Clin (Barc). 2007;129(9): 326-332.

8. Stewart AL, Mills KM, King AC, McLellan BY, Roitz KB, Ritter PL. Evaluation of CHAMPS, a physical activity promotion program for older adults. Ann Behav Med. 1997;19(4):353-61.

9. Falck RS, McDonald SM, Beets MW, Brazendale K, Liu-Ambrose T. Measurement of physical activity in older adult interventions: a systematic review. Br J Sports Med. 2015 Aug. doi: 10.1136/ bjsports-2014-094413

10. Stewart AL, Mills KM, King AC, Haskell WL, Gillis D, Ritter PL. CHAMPS physical activity questionnaire for older adults: outcomes for interventions. Med Sci Sports Exerc. 2001;33(7):1126-41.

11. Rosario MG, Vázquez JM, Cruz WI, Ortiz A. Internal consistency of the CHAMPS physical activity questionnaire for Spanish speaking older adults. P R Health Sci J. 2008;27(3):224-8.

12. Harada ND, Chiu V, King AC, Stewart AL. An evaluation of three self-report physical activity instruments for older adults. Med Sci Sports Exerc. 2001;33(6): 962-70.

13. Lobo A, Saz P, Marcos G, Día JL, De La Cámara C, Ventura $\mathrm{T}$, et al. Revalidation and standardization of the cognition mini-exam (first Spanish version of the Mini-Mental Status Examination) in the general geriatric population. Med Clin. 1999; 5;112(20):767-74.

14. De la Iglesia JM, Herrero RD, Vilches MCO. Cross-cultural adaptation and validation of Pfeiffer's test (Short Portable Mental Status Questionnaire [SPMSQ]) to screen cognitive impairment in general population aged 65 or older. Med Clin. 2001;116(4), 129-134.

15. Hekler EB, Buman MP, Haskell WL, Conway TL, Cain KL, Sallis JF, et al. Reliability and validity of CHAMPS self-reported sedentary-to-vigorous intensity physical activity in older adults. J Phys Act Health. 2012;9(2):225-36.

16. Kelly LA, McMillan DG, Anderson A, Fippinger M, Fillerup G, Rider J. Validity of actigraphs uniaxial and triaxial accelerometers for assessment of physical activity in adults in laboratory conditions. BMC Med Phys. 2013 26;13(1):5. doi: 10.1186/1756-6649-13-5.

17. Yasunaga A, Park H, Watanabe E, Togo F, Park S, Shephard RJ, et al. (2007). Development and evaluation of the physical activity questionnaire for elderly Japanese: the Nakanojo Study. J Aging Phys Act. 2007;15(4):398-411.

18. Silva-Batista C, Urso RP, Silva AEL, Bertuzzi R. (2013). Associations Between Fitness Tests and the International Physical Activity Questionnaire-Short Form in Healthy Men. J Strength Cond Res. 2013;27(12):3481-7. doi: 10.1519/ JSC.0b013e31828flefa.

19. Cabañero-Martínez MJ, Cabrero-García J, Richart-Martínez M, Muñoz-Mendoza CL. The Spanish versions of the Barthel index (BI) and the Katz index (KI) of activities of daily living (ADL): A structured review. Arch Gerontol Geriatr. 2009;49(1):e77-84. doi: 10.1016/j.archger.2008.09.006. Epub 2008 Nov 5.

20. Guralnik JM, Simonsick EM, Ferrucci L, Glynn RJ, Berkman LF, Blazer DG, et al. A short physical performance battery assessing lower extremity function: association with self-reported disability and prediction of mortality and nursing home admission. J Gerontol. 1994;49(2):M85-94.

21. Arnardottir NY, Koster A, Van Domelen DR, Brychta RJ, Caserotti P, Eiriksdottir G, et al. Objective measurements of daily physical activity patterns and sedentary behaviour in older adults: Age, Gene/Environment Susceptibility-Reykjavik Study. Age Ageing. 2013;42(2):222-9. doi: 10.1093/ageing/afs160

22. García-Massó X, Serra-Añó P, García-Raffi LM, Sánchez-Pérez EA, López-Pascual J, Gonzalez LM. Validation of the use of Actigraph GT3X accelerometers to estimate energy expenditure in full time manual wheelchair users with spinal cord injury. Spinal Cord. 2013;51(12):898-903. doi: 10.1038/sc.2013.85.

23. Colbert LH, Matthews CE, Havighurst TC, Kim K, Schoeller DA. Comparative validity of physical activity measures in older adults. Med Sci Sports Exerc. 2011;43(5):867-76. doi: 10.1249/ MSS.0b013e3181fc7162.

24. Giles K, Marshall AL. The repeatability and accuracy of CHAMPS as a measure of physical activity in a community sample of older Australian adults. J Phys Act Health. 2009;6(2): 221-229.

25. Gennuso KP, Matthews CE, Colbert LH. Reliability and validity of 2 self-report measures to assess sedentary behavior in older adults. J Phys Act Health. 2015; 12(5): 727-732.

26. Resnicow K, McCarty F, Blissett D, Wang T, Heitzler C, Lee RE. Validity of a modified CHAMPS physical activity questionnaire among African-Americans. Med Sci Sports Exerc. 2003;35(9):1537-45.

27. Soyuer F, Şenol V. Fatigue and physical activity levels of 65 and over older people living in rest home. Int J Gerontol. 2011;5(1):1316. doi: 10.1016/j.ijge.2011.01.003

28. Resnick B, King A, Riebe D, Ory M. Measuring Physical Activity in Older Adults Use of the Community Health Activities Model Program for Seniors Physical Activity Questionnaire and the Yale Physical Activity Survey in Three Behavior Change Consortium Studies. West J Nurs Res. 2008;30(6):673-89. doi: 10.1177/0193945907311320

29. Hauer K, Lord SR, Lindemann U, Lamb SE, Aminian K, Schwenk M. Assessment of physical activity in older people with and without cognitive impairment. J Aging Phys Act. 2011;19(4):347-72. 
30. Lautenschlager NT, Cox KL, Flicker L, Foster JK, van Bockxmeer FM, Xiao J, et al. Effect of physical activity on cognitive function in older adults at risk for Alzheimer disease: a randomized trial. JAMA. 2008 ;3;300(9):1027-37. doi: 10.1001/jama.300.9.1027

31. Moore DS, Ellis R, Allen PD, Monroe PA, Cherry KE, O'Neil CE, et al. Construct validation of physical activity surveys in culturally diverse older adults: a comparison of four commonly used questionnaires. Res Q Exerc Sport. 2008;79(1):42-50.

32. Cyarto EV, Marshall AL, Dickinson RK, Brown WJ. Measurement properties of the CHAMPS physical activity questionnaire in a sample of older Australians. J Sci Med Sport. 2006;9(4):319-26

33. Bohannon RW. Reference values for the five-repetition sit-to-stand test: a descriptive meta-analysis of data from elders. Percept Mot Skills. 2006;103(1):215-22.

34. Fogelholm M, Malmberg J, Suni J, Santtila M, Kyröläinen H, Mäntysaari M, et al. International physical activity questionnaire: validity against fitness. Med Sci Sports Exerc. 2006;38(4):753-60.

\section{Corresponding author}

Miguel A. Sánchez-Lastra

Healthyfit Research Group, Faculty of Educational Sciences and Sports, University of Vigo, Campus A Xunqueira s/n E-36005 Pontevedra, Spain.

Email: misanchez@uvigo.es

Manuscript received on August 03, 2016

Manuscript accepted on August 24, 2016

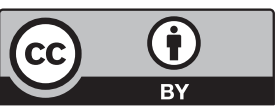

Motriz. The Journal of Physical Education. UNESP. Rio Claro, SP, Brazil - eISSN: 1980-6574 - under a license Creative Commons - Version 3.0 